Lancaster University Management School:

Author Accepted Manuscript

This is an 'accepted manuscript' as required by HEFCE's Open Access policy for REF2021.

Please cite this paper as:

\title{
Rethinking global leadership development programmes: the interrelated significance of power, context and identity
}

Gagnon, S. \& Collinson, D. In Organization Studies.

ACCEPTED FOR PUBLICATION August 20th 2013

ORCID NUMBER: 0000-0002-0884-9960

DOI: [Insert DOI number if assigned on acceptance e.g. 10.1177/1470593117702286 ]

David Collinson

Distinguished Professor of Leadership and Organisation

Lancaster University Management School

Lancaster, LA1 4YX

\section{f日通 in}

TRIPLE-ACCREDITED, WORLD-RANKED

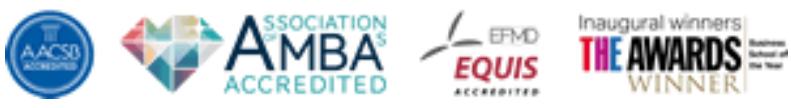




\title{
Rethinking Global Leadership Development Programmes through Critical Identity Theory
}

\begin{abstract}
Organization studies scholars have examined leadership development processes on only a handful of occasions. This article argues that an organizational lens, in contrast to individualized and contextindependent research can significantly advance this under-theorized field. A critical organizational framing, in particular, assists not only in problematizing the 'leader' identities produced within contemporary leadership development programmes (LDPs), but also in surfacing the power relations, tensions and contradictions underpinning these dynamics The article contributes to critical leadership and organization studies in three main ways. First, it theorizes through a critical identity lens the regulatory practices that constitute an idealized leader self in two separate global LDPs. 'Identitytargeting' practices create tensions and paradoxes rarely examined in studies of LDPs and organizations more generally. Second, it examines participants' considerable resistance to the prevailing models of global leader prescribed in the two LDPs. Their opposition is connected to the internationally diverse character of these LDP cohorts. Third, our dual case analysis highlights the role of discursive context, enabling us to compare two particular strategies of leadership development through identity regulation, which we label 'investiture' and 'divestiture.' The paper concludes by discussing the implications of this analysis for rethinking theory and practice, and suggests future research directions for critical organization studies of leadership and LDPs.
\end{abstract}

\section{Keywords}

Critical leadership studies, leadership development, identity-targeting, critical identity theory, prescribed leader identities, divestiture, investiture

\section{Introduction}

In recent years the idea that identities can be shaped by dominant organizational discourses and practices has become a central notion within critical organization studies (Alvesson \& Willmott, 2002; Kenny, Whittle \& Willmott, 2011; Thomas, 2009). Yet these critical perspectives have tended to concentrate on management to the neglect of leadership as a field of analysis, viewing the latter area as more suited to work focussed on practitioners, and informed by functionalist and normative research orientations. Conversely, within leadership studies, critical analyses of identity regulation are significantly under-explored. Studies that do examine identity dynamics tend to adopt a more narrow 
psychological perspective (Haslam, Reicher \& Platow, 2011), often focusing on the ways in which (transformational) leaders can (and should) shape followers' identities (Burns, 1978; Shamir, House \& Arthur, 1993; Lord \& Brown, 2004) and/or the extent to which leaders' identities are 'prototypical' for their followers' identities (Hogg, 2001). Discourse oriented studies of leadership development have tended to examine identity work connected to leadership as individualized, with less attention paid to organizational discursive contexts (Carroll \& Levy, 2008), while emerging psychodynamic perspectives have focused on conscious and subconscious identity processes internal to the 'leader' (Petriglieri \& Stein, 2012).

Informed by a critical approach to identity dynamics in organizational contexts, this paper examines the regulatory and transformative practices of two leadership development programmes (LDPs) for senior employees in two multinational corporations. In both cases programme discursive practices sought to align participants' identities and behaviours with the construction of a particular ideal leader. The article sets out the main characteristics of these prescribed leader selves and examines the discursive practices through which these identities were targeted and re-built. Although the LDPs shared a number of similarities in structure and design, the two cases also reveal differing orientations or 'meso-level discourses' of leader development shaped by particular corporate objectives, producing different consequences for participants and their organizations (Alvesson \& Karreman, 2000). In addition, the identity-targeting processes evident in both programmes were not simple, top-down, or all-determining. A number of tensions and inconsistencies, often highlighted by research respondents themselves, characterized many of the practices we observed. Such tensions are important, we argue, in developing a theoretically grounded analysis which conceptualizes LDPs not only as sites of learning and skill development, but also as complex and sometimes paradoxical processes through which dynamics of power and identity are enacted and reproduced.

The paper seeks to extend the literature in critical leadership studies and LDPs in three main ways. First, through a critical identity lens, it examines the development practices of elite organizational leaders in two particular settings, highlighting how 'regulation' produces particular implications rarely examined in previous studies of LDPs. Second, it explores participants' considerable 
resistance to the prevailing models of global leader prescribed in the two LDPs. Their opposition is connected to the internationally diverse nature of these LDP cohorts. Actors' resistant practices are important, we argue, in understanding broader implications for leadership in globalizing business contexts. Third, the article identifies and compares two particular strategies of leadership development through identity regulation, which we label 'investiture' and 'divestiture.' A key distinguishing feature of the two types is the degree of participant insecurity, both subjective and material, embedded and reproduced within programme practices.

To understand these dynamics, the paper begins by reviewing perspectives in critical identity theory and addresses particular issues in researching LDPs. We then outline our research methods followed by a review of the empirical findings, which are organized into three sections. The paper concludes by considering how this analysis can contribute to the development of critical approaches to leadership and organization studies.

\section{'Critical identity theory'}

The practices through which identity work may be shaped through discourse are the subject of a growing literature in more critical organization studies (Bergstrom, Hasselbladh \& Karreman, 2009; Brown, 2001; Brown \& Lewis, 2011; Collinson, 2003; Hodgson, 2005; Karreman \& Alvesson, 2004; Kenny, Whittle \& Willmott, 2011; Thomas, 2009; Thomas \& Davies, 2005; Thornborrow \& Brown, 2009). Central within what we label 'critical identity theory' are Foucault's $(1977,1979)$ ideas on power, knowledge, discourse, subjectivity, and their inter-relations. Although influential in organizational and management studies, this work has so far had less impact on the study of leadership generally (c.f. Fairhurst, 2008) and of LDPs in particular. Traditionally tending to steer away from 'leadership' (focusing on management and organization as their area of study), critical perspectives constitute a comparatively new approach to leadership studies (Alvesson \& Spicer, 2012; Collinson, 2012; Tourish, 2013). Critiquing the power relations through which leadership dynamics are frequently reproduced, sometimes resisted, and occasionally transformed (Gordon, 2002; Nye, 2008; Tourish \& Vatcha, 2005) and informed by an eclectic set of perspectives, critical leadership studies challenge views in the 
mainstream leadership literature which take for granted that leaders are the people in charge who make decisions while followers are those who merely carry out orders from 'above' (Collinson, 2011). Complex inter-relations with gender as well as the centrality of social context for constructions of leadership are also emerging themes within this literature (c.f. Ford, 2006).

Foucault $(1977,1979)$ focuses on power and identity dynamics, arguing that practices of disciplinary power produce subjectivities, for example, through normalization, a process by which the eccentricities of human beings are measured and if necessary corrected. As a form of power that disciplines the self, normalization constructs identity and knowledge by comparing, differentiating, hierarchizing, homogenizing, and excluding. Foucault explores the disciplinary power of surveillance that produces detailed information about individuals, rendering them visible, calculable, and selfdisciplining selves. The condition of being a subject is created by particular discourses and practices, or what he labeled the 'power/knowledge regimes', in which we all reside. Identity as subjectivity expresses an epistemological position in which individuals are recognized as both subjects (active, knowledgeable, creative agents) and objects (shaped by structures, discourses, and cultures, and subject to observation and monitoring).

These ideas have informed research exploring the mutually-constituting relationship between power and identity (Ashcraft, 2005; Brown \& Lewis, 2011; Covaleski, Dirsmith, Heian \& Samuel, 1998; Jaros, 2012; Townley, 1993). This scholarship suggests that any analysis of individuals' identity work must engage with organizational practices and discourses and their 'power effects'. Studies have considered how identities are constructed and monitored in the workplace (Brown \& Coupland, 2005; Casey, 1999; Fleming \& Sewell, 2002; Fleming \& Spicer, 2003; Thomas, Mills \& Mills, 2004; Willmott, 1993). Many of these writers highlight the disciplinary and constraining effects of power relations and their tendency to produce conformity and/or compliance.

Alvesson and Willmott's (2002) conceptual model of 'identity regulation' draws explicitly on the work of Foucault. Arguing that loyalty and identification can no longer be taken for granted but must be actively created in contemporary organizations, they consider how employees are encouraged to develop self-images and work orientations that are deemed congruent with managerially defined 
objectives. This echoes earlier work on contemporary control which argues that "it is the employee's self - that ineffable source of subjective experience - that is claimed in the corporate interest" (Barley \& Kunda, 1992, p.11). Alvesson and Willmott (2002) theorize the interplay between self-identity (the precarious outcome of identity work comprising narratives of self), identity work (interpretive activity involved in reproducing and transforming self-identity), and the regulation of identity (discursive practices concerned with identity definition that condition processes of identity construction). They also pinpoint a series of workplace processes that regulate identity by defining: the person directly; $a$ person by defining others; a specific vocabulary of motives; morals and values; knowledge and skills; group categorization and affiliation; hierarchical location; rules of the game; and the context.

While identity regulation is a pervasive and increasingly intentional modality of organizational control, it is not necessarily effective, Alvesson and Willmott contend, in increasing employee commitment or loyalty. Indeed earlier and subsequent studies have noted the potential of identity regulation to spark dissent. Pursuing the theme of the agent as subject (as well as object), and informed by Foucault's emphasis on the intrinsic interconnections between power and resistance, some critical authors argue that workplace disciplinarity often generates opposition (e.g. Jermier, Knights \& Nord, 1994; Prasad \& Prasad, 1998, 2005; Thomas \& Davies, 2005). They show how resistance in contemporary organizations can be expressed in multiple, complex ways, for example, through overt practices such as strikes and formal appeals, to more covert and disguised processes including output restriction or 'distancing' (Collinson 2003). These studies also often connect dissent to subjectivity revealing, for example, how individuals may resist in order to restore, assert, or re-define their sense of self (Collinson, 1992; Mumby, 2005). Thus, far from being passive receptacles of organizational identityshaping discourses, employees' engagement with these operate not only as (potential) mechanisms of control and discipline, but also as opportunities for more oppositional discursive practices and resistance (Ashcraft, 2005). ${ }^{\mathrm{i}}$

Thus, although this literature focuses on identity as an aspect of organizational control, the subjective experience of workplace identity dynamics - accounts and experiences of the subject as agent —remain highly important (Zanoni \& Janssens, 2007). “Power relations are subjectively 
experienced" and identity is a "specific, historical product embedded within particular conditions and power relations" (Collinson, 1994, p.52-53). As the situated context of identity work is critically important to understanding subjective experience, the following analysis seeks to foreground, in particular, the analytical significance of participants' experiences in relation to identity processes that emerged in our case organizations. By exploring leadership development through critical identity theory, this paper is concerned to reveal how participant identities were 'targeted' in programme dynamics. In so doing, it also focuses specifically on aspiring leaders and senior managers. The impact of identity regulation on such senior-level employees has typically received much less attention in the literature.

\section{Researching leader development programmes}

Identifying and developing organizational leaders is a major corporate concern. Significant investment in LDPs for mid-level and senior executives reflects a prevailing view in many Western societies that effective leadership is a key factor in organizational success. One estimate cites a \$45 billion annual expenditure in the U.S. alone for leadership development (Day, 2011) and a survey of European CEOs found that the majority was "extremely" committed to leadership development (Buus \& Saslow, 2005). Although firms may employ a variety of means for building employees' leadership abilities, surveys indicate that a high proportion adopt formal LDPs. More than half of some 1,500 firms in one global study had their own 'corporate university' to provide leadership training, and half also had customized leadership programmes (Jamrog, 2005). Such programmes typically involve 'high-potential' employees, current executives, or mid-level managers (Hughes \& Grant, 2007). As Mabey and Finch-

Lees (2008) observe, LDPs comprise a "potent and high-profile human resources activity, involving some of the organization's key players and attracting high investment both in terms of corporate budgets and expectations" (p.3).

There has been relatively little attention, however, in the operation and effects of such programmes, including a lack of qualitative research (vvolio, Richard, Hannah, Walumba \& Chan, 2009) and few empirical studies geared to theory development (Bolden \& Gosling, 2006; Mabey \& Finch-Lees, 2008; Mabey, 2012). Much extant research on LDPs is prescriptive in tone, focusing on competency- 
creation and tending to be context-free, disregarding the social, organizational and political settings in which LDPs are embedded. Our approach explores the symbolic and discursive value of LDPs beyond their role as vehicles for learning particular capabilities or skills, seeking to understand participants as social actors within situated employment relationships in particular organizational contexts. In addition, extant research has often taken for granted the particular model of leader embedded and reproduced through specific programmes. By contrast with mainstream studies that advocate prescription of specified qualities as "an indispensable component of leader development" (Day, Harrison \& Halpin, 2009, p. 183), we suggest that a central element underpinning this prescription involves identitytargeting practices.

Studies linking leadership development and identity have recently emerged, but these have tended to focus on individual cognitive processes or interpersonal interaction, almost uniformly sidestepping the role of employer or organizational discourse and power in the shaping of leader identities. This research has used concepts of identity in connection to leader development in a number of ways, for example by: i) linking the development of leadership ability to an individual's cultivation of a more sophisticated and non-self-oriented personal identity as part of the process of maturing as a leader (Lord \& Hall, 2005); ii) conceptualizing leadership as the building of a shared or collective identity among followers (Haslam et al., 2011); iii) analyzing a leader identity as being co-created through social interaction, based on an individual claiming or being granted through cognition or behavior a selfconception that matches his or her cognitive schema of a leader (DeRue \& Ashford, 2010); and iv) identifying role tensions for managers undertaking leadership development as identity conflicts (Carden \& Callahan, 2007), and addressing incongruities associated with participants' work and non-work selves.

The first three studies above draw on identity frames to assist in understanding an individual's path to leadership, and clearly there are interactive and recursive processes, particularly in DeRue and Ashford's (2010) work and others' who have adopted this view (e.g. ; Ely, Ibarra \& Kolb, 2011), which define 'leader'. However, Carden and Callahan's (2007) study has the most resonance for our analysis, as it suggests that a formal LDP prescribes a particular identity for its participants, which they then may take up or perhaps resist (e.g., should a participant be willing to sacrifice the personal time, for 
example, required of 'leadership' in the programme context?). Their approach thus calls attention to participants' experiences of identity regulation and to the situated nature of 'becoming a leader'.

Subjective experiences are also important in another recent study revealing how difficult it was for development participants to move from their 'default identity' as 'manager' to an emergent 'leader' identity, given the latter's perceived ambiguous qualities (Carroll \& Levy, 2008). Respondents found it easier to say what leadership was not, than to specify what it was. This study also exemplified the allure of the leader identity for managers seeking to re-define themselves as leaders and the esteem associated with 'leader' qualities, such as being visionary and inspirational, even though these seemed nebulous or ill-defined.

Finally, we are guided by Ackers and Preston's (1997) study of the ethicality of contemporary management development operating as a type of religious conversion that 're-moulds individual personality" and hence corporate culture. They ask, "does a largely involuntary business organization have an ethical right to claim the 'souls' of its managers?" (p. 677). Their study suggests that the use of emotional experience within management development tends to aim in that direction, and also assesses the degree to which such an endeavour can be successful. To summarize, there have been few critical studies of LDPs, and it is in this context that the current article seeks to contribute.

\section{Research design}

The original aim of this research was to investigate the social and political dynamics of corporate leader development programmes from the point of view of internationally diverse participants. We were interested in understanding LDPs 'in the round', beyond the lens of programme pedagogy or functional effectiveness, as political processes embedded in organizational cultures and employment relations. We chose a dual case study design to enable a detailed examination of the situated context of LDPs, distinct from the individual-level analyses dominating this field. Our interest in these two international LDPs in particular stemmed from their similarity in structure, design, and membership diversity, while also operating within contrasting corporate contexts and cultures. 
The concept of identity regulation was not part of the initial analysis but emerged as an important theme during the course of the research. Iterating the analysis of our data with consideration of the literature, we identified attempts to control identities or subjectivities as a sensitizing concept to guide subsequent analysis (Barker, 1993), using a discursive epistemology of identity dynamics based on Foucault's conception of discourse $(1972,1977)$. While discourse has been most commonly used to denote speech, conversation, text, or a body of knowledge, for Foucault the term transcends these, "endowing them with an additional layer of institutional materiality as well” (Prasad, 2005, p. 250). Hence, discourses are viewed here, not as abstract or disembodied texts, but rather as active processes working in the realm of materiality, in the domain of specific historical practices and objects (Prasad, 2005). ${ }^{i .}$ They are embedded in and interwoven with context.

\section{Research Sites}

The findings of this study draw on fieldwork conducted over 16 months between 2005 and late 2006 in two LDPs. Both programmes were largely designed 'in house' to serve corporate strategic priorities. Their participant cohorts comprised groups of some 25 senior and middle managers, selected from large pools. One programme ran annually, the other every 18 months. Both combined periods of workshop instruction with 'live' projects completed in cross-functional teams of 6 or 7 participants, with a key role for senior executives as presenters, evaluators, team coaches, or sponsors. The stated aims of these programmes included preparing participants for future leadership roles that require cross-functional and cross-regional knowledge. Access negotiations lasted several months and other firms were approached during this time. Programme directors granted access in return for anonymized executive reports of participant feedback on the programmes.

The first programme, TGMP or Top Global Managers Programme (pseudonym), was located in a profitable multinational operating within an industry that is declining in some parts of the world. With headquarters in Europe, the firm's strategy was to acquire operational plants in promising international markets within generally less economically developed regions. TGMP was initially designed to develop senior local managers of newly acquired plants. The company wished to educate its managers in 
Western management techniques and develop the most promising candidates into corporate-level leaders. The programme was then expanded to include managers from some 70 countries. The cohort in our study was the third to undergo the programme and included 25 managers from 14 different locations, representing 20 nationalities. Their average age was 36 and average tenure 8.5 years. The original programme content had been broadened from cross-functional knowledge and business leadership to include teamwork, team leadership, and peer feedback. The taught portion comprised three 2-week residential modules held at an executive business school. Four project teams were assigned corporate-level projects to complete over 8 months, which they then presented to the corporate executive. The programme director estimated the approximate cost per participant at US\$100,000.

We label the second firm's programme GAL, for Global Agency Leaders (pseudonym). In this case, the employer is a longstanding international industry agency with one head office in North America and one in Europe. It is a non-profit body that develops standards and provides services to members, employing some 1,400 professional staff working in 70 countries. GAL is an intensive 5-month programme consisting of three workshops that are a few days each, facilitated by consultants, the director of training, and senior executives. Our research involved the $2^{\text {nd }}$ cohort to undertake the programme, representing 16 nationalities. Participants' average age was 37, ranging from mid-20s to mid-50s. A few were selected after only one year of service with the firm, and the maximum tenure was 16 years. Four teams were each assigned a major project for which they were given five months to complete. The programme ended with group presentations to the Director General and senior executives. Table 1 sets out the then-current work locations and nationalities of participants in both LDPs. 


\section{Data Collection}

To capture the complexity and singularity of each case, ethnographic fieldwork in these two sites examined the contexts of the LDPs as much as access would permit (Easterby-Smith, Thorpe \& Lowe, 2008), including archival research such as competency frames and participant evaluations (for TGMP) and non-participant observation of programme-related events. Research interviewees included participants, coaches (former GAL participants), and programme directors. Solicited by means of e-mail requests, nearly all programme participants agreed to be interviewed ( 24 of 24 participants in GAL, and 23 of 25 in TGMP). Interviews were conducted during the final third of TGMP and in the few weeks after programme completion for GAL. Interviews with the directors took place on several occasions during this same period, as well as informal conversations with participants on an 'as possible' basis. For one firm, this included a two-day visit by one of the authors to the business school where participants were undertaking workshops. Table 2 sets out the interviews conducted for the study.iii Remaining mindful of one's 'reflexive screens' and maintaining an openness and other-focus were important in both the conduct of the interviews and in the analysis (Patton, 2002; Rhodes, 2009).

Table 2 about here

This methodology allowed us to gather multiple-source data on key programme elements, enabling triangulation on interpretive issues (e.g., the politics of selection) and more 'factual' matters (e.g., promotion and retention). Interviews were 60 minutes in length on average, with the longest extending to 120 minutes and the shortest 35 minutes. The additional interviews with both programme directors over the subsequent 12 months ( 3 for TGMP, 5 for GAL) explored each LDP's evolution and participants' career progress since completion. Interviews lasting 60-90 minutes were held one year later with three participants in each programme, chosen in part due to opportunity of access but also with consideration to their high degree of interest and participation in the earlier interviews. ${ }^{\text {iv }}$ The 
study produced extensive interview transcripts, memos, and other materials. Full transcripts of the interviews, all conducted in English, were produced professionally. A small number of interviews were not taped, in two cases due to participant preference, but extensive notes were taken in every case. Participant and coach interviews ranged from the longest at 26,070 words (53 pages), to the shortest at 3,911 words (12 pages). The average length was 11,110 words, or 24 pages.

\section{Data Analysis}

Consistent with our epistemological approach, we took participants' accounts as "retrospective explanations and justifications in shaping and constituting organizational practices" (Prasad \& Prasad, 2000). The practices of leadership development in these two contexts were our main object of analysis; we worked to understand these as re-constructed by the participants and other informants. Starting with an 'open coding' approach (Strauss, 1987), we combined general readings for broad themes with more detailed analysis, using constant comparison to begin to discern patterns in the materials (Locke, 2001). We produced a series of memos on each site, aiming to understand each before comparing and contrasting across the two programmes (Stake, 1995), iterating between the data and the literature. An early theme involved the strong sense in which participants were asked to become cultural actors for their employers, as they worked to learn particular leader models apparently aligned with organizational objectives. As our attention turned to examining in detail the practices through which this was achieved or attempted in each of the LDPs, the issues of subjectivity, identity and disciplinarity became increasingly important. We recognized the importance of problematizing the idealized leader self embedded within the programmes, surmising that this may be a notable point of variation between the two LDPs. This permitted us to ask questions about how LDPs may constitute an espoused leader identity: what was this model in the different settings? Through what discourses and practices was this defined, reproduced and sustained? These basic questions allowed particular themes to emerge that we could then compare and revise in continuing the analysis, while continuing to iterate between emerging findings and the literature, conducting more detailed coding of practices in the two sites, and then collapsing the categories until we had reached a point of saturation and an understanding of the main practices. ${ }^{v}$ In the empirical sections below, we draw on 
the data first to illustrate the identity-targeting practices found in both programmes, and then to highlight key differences between the two LDPs.

\section{Targeting identities in LDPs}

Both LDPs targeted participants' selves by prescribing and reinforcing a particular idealized leader identity. These processes were found to constitute discursive and material practices that defined who could (and could not) be a leader, as well as which identities or subject positions were acceptable and which were not. Yet, these regulatory programme practices were by no means all-determining or controlling in any simple, top-down sense. The following discussion also emphasizes the tensions and contradictions embedded in these identity targeting practices.

\section{Prescribing the idealized leader identity}

In each LDP we found a set of practices focused on defining and prescribing a particular valued and idealized 'leader' identity, which began with explicit statements of the preferred profile of a leader. Often explicated in a competency framework that specifies desired qualities and traits (Finch-Lees, Mabey \& Liefooghe, 2005), such profiles 'define the person directly' (Alvesson \& Willmott, 2002). For both TGMP and GAL, the specifications of leader qualities were frequently emphasized. TGMP had a formal framework specifying: "a sense of urgency and speed; anticipation, decisiveness and risk-taking; passion for getting the most difficult things done; confidence, humility, integrity; listening, learning, sharing, teaching." Participants were required to use this framework to give peer feedback. The GAL selection materials called for "ideas, values, energy and edge." " Boldness, risk-taking, initiative, and 'a results-focus' were constants in the director's and coaches' programme rhetoric, deemed to be leader qualities essential to shift the firm away from a 'plodding', conflict-averse culture. These leader requirements were reproduced through an array of discursive practices explicitly prescribing a particular leader self, as follows:

The leader as special and deserving. 'Specialness' and merit were tenets of membership in both programmes, and provided a channel for pursuing career ambitions resonating with wider societal 
values that privilege 'leader', 'global leader', or 'global manager' identities. An elite and special leader identity was defined through several LDP practices. The first was the label 'leader' itself, which is a title or 'ascribed marker' that can engender a sense of being special and distinct, providing the individual with an elite social identity that is likely to 'fashion superior selves' (Schwalbe, Godwin, Holder et al. 2000 , p. 425). Second, the exclusiveness of the programmes -25 employees only, chosen from large, international employee pools - created a space of privilege to which only a few would attain entry. Company documents and internal websites presented both programmes as high-status opportunities for those deemed to be top performers, thus, constructing a discourse of exclusivity and superiority. TGMP applications were accepted from anyone at middle management level, anywhere in the firm. Applicants were extensively assessed and tested before being granted entry, including through the Graduate Management Admission Test (GMAT). Several dozen were then invited to a day-long assessment and those deemed most qualified went forward into the cohort. For GAL, senior executives were asked to propose names of candidates, whose relative merits were then discussed in detail and accepted or rejected at a meeting of the executive team.

In practice, however, participants' accounts of these processes suggest scepticism about the programmes' claims to exclusivity. In TGMP, some spoke about trying to remain humble and discrete vis-à-vis their regular colleagues, not wishing to 'lord it over' them, as one participant put it (TGMP2 M). Another said there was certainly a 'caché' about the moniker 'TGMP', yet he found the title and rhetoric around it to be 'over the top': "We're not 'global' let alone 'world-class"' (TGMP9 M). vii Nonetheless he said he was proud to have been selected. Within GAL, similar mixed emotions were heightened through a degree of compulsion in the selection process. Several participants said they had 'no choice' but to apply and a number criticized its compulsory element. Overall, although the two LDPs validated participants' identities as special and deserving, some respondents expressed considerable ambivalence about such claims.

Programme rhetoric further emphasized the leader identity as earned and thus deserved, based on merit rather than hierarchical position, seniority, or personal connections. In both LDPs, participants of a variety of tenures and histories were grouped together on a formally 'equal' basis. This 
was expressed in GAL through the phrase 'leave your stripes at home' where hierarchical difference was 'stripped away' for programme participants:

We were all thrown together, we all left our stripes at home -junior managers and directors were talking at the same level, making decisions and participating at the same level. It allowed individual qualities to come out ... rather than who we were on paper ... Certainly the leadership drilled it into us that we were all the same; if a senior person on a team automatically assumes they are the leader, it was made very clear that wasn't the case, we were there to all strive for that (GAL coach2 M).

This discourse of equality and sameness contradicted broader messages of elite status as well as longstanding hierarchical differences and inequality among participants, which were then reinforced through subsequent evaluations of participants.

The leader as pressure-loving and 'on edge'. The LDPs constructed highly pressurized environments, such as arduous workloads and tight deadlines, which ostensibly mimicked the toughness required for leadership in the context of 'real-world' challenges. This also ensured that participants were often 'on edge', i.e., uncertain and to some extent insecure. While such 'pressure loving' discourses were present in both programmes, they were more pronounced within GAL. Here, the meaning of required 'leader' was tightly associated with personal resilience and drive. Several participants stated that the work on GAL required double their normal work time, as opposed to the $25 \%$ more indicated by programme materials. They were not given leave from their regular positions nor able to retain planned vacations. One woman who did not cancel her vacation was later chastised by her sponsor and subsequently punished (in her view) at the time of her performance evaluation.

Rigid schedules, crossing multiple time zones for workshops with no downtime, conference calls during the night, no breaks between programme segments, and missed family occasions further reinforced a discourse of toughness and 'doing what is necessary to lead'. While some commented on the sometimes 'manufactured' feel of the rigid deadlines, such schedules left little room for competing loyalties or identities (c.f. Carden \& Callahan, 2007). Nearly all TGMP participants also noted a significant toll on personal lives and time. 
To exemplify a desired leader identity that embraces pressure and thrives on adversity, the intensified workload on GAL was designed to reveal who could endure the stress: "We push people to their breaking limit; (GAL) really does stretch people. And they're expected to continue doing an outstanding job in their day jobs" (GAL Dir M). The programme sought to differentiate between those who could cope with the intensified workload and those who could not. Participants were expected to "take it like a man" (GAL23 M) as another person said, voicing the underlying masculine assumptions informing the idealized, 'tough' leader devoted to 'his' work to the exclusion of all else.

They want to know what we are made of. You have to have the right fibre. GAL is the first stepping stone to having senior employees who can be double-and triple-tasked. This is quite clear to me now (GAL23 M).

Even though participants decried the workload, many accepted it as necessary. Recounting how she "worked like hell," one participant stated:

My group got the impression after the first workshop, when I was in shock, that I was quiet, very shy and not able to express myself, and it was so true. I was so stressed by the environment. So my plan was to work harder than all of them, to prove myself (GAL2 F).

Although TGMP similarly prescribed a leader identity which thrived on stress even in a continual state of uncertainty, this was mitigated by regular opportunities for socializing among participants, a slower overall pace, and coursework in two-week periods with leave from regular responsibilities.

The leader as hyper-rational and decisive. The practice of 'letting people go' who were not deemed to fit the favoured model was a highly visible method of defining the prescribed leader identity in the GAL programme. The open termination of four participants while the programme was still underway reinforced the dominant discourse of resilience and decisiveness, emphasized the critical element of competition, and reinforced a culture of insecurity among participants. The director explained such actions to the researcher and to participants as 'rational', 'necessary', and 'demonstrating decisiveness', asserting that the choice to terminate people who are less competitive 
was an important part of what leaders do and must be prepared to do. GAL members were expected to share this view and, in so doing, understand their own membership as more exclusive. The management team conducted three assessments of all participants, which could result in termination depending on the committee's view of the participant's fitness for future leadership in the company. Three weeks following the end of GAL, one participant from each of the four project groups had been fired. At the time of writing, only one participant has been promoted. One year after this cohort began the programme, four additional GAL participants were terminated from the company.

A hyper-rational leader identity was further reproduced within GAL through a forced ranking exercise in which project team members were required to evaluate and rate one another as to who they believed was the best leader. Twice during the programme, team members were given a strictly limited timeframe (30 minutes) in which they were asked individually to rank one another — \#1 as the best to \#7 as the weakest - after spending a few days in one another's company. According to the director, the exercise instilled the important leadership ability to take swift, decisive action on challenging and sensitive tasks. One coach argued that even those who were uncomfortable with it:

...learned a lot. Because we push them to be open, frank, and to show edge. To verbalize (their rankings of others) for a lot of people was very difficult. We made them do it... People had to take ownership. They got very quiet actually, and I pushed them to explain it. Why do you say this person is the leader here? Why do you say that person has a lot to learn, and that person is just not there yet? Some of them overcame that inhibition and expressed it, and this overcame two barriers. One is to tell somebody to their face what you think, and the other is to actually take ownership of your assessment (GAL coach1, M).

The forced ranking exercise clearly intensified participants' sense of insecurity and of being 'under the gaze'. The following comment describes how GAL participants were given little explanation about why certain individuals were abruptly terminated:

We're never told the ins and outs of why people leave or have left. But you usually know. For instance, there was one director from this year's GAL, and one from last year; neither of them wanted to leave but the circumstances surrounding their departure meant they had to leave. Whatever the company needed wasn't in line with what the person was doing. But they were on GAL, so you would have assumed they would have been okay, in the sense that they should have been 'the best of the best', as we were told. You're not thinking of going there to fail, you're thinking of going there because you've succeeded and 
you will succeed more.... But the other side is that maybe these people got it wrong, and the programme has highlighted the fact that they're not going to succeed or they're doing things they shouldn't be doing. And so they have to go... (GAL22 F).

Despite the lack of information and a certain sense of unfairness, this respondent still concurs that these termination decisions were rational, based on merit and the result of 'decisive decisionmaking'. The underlying message of this intensified evaluation is again that participants need to become the leader required on the programme, to embrace pressure and be continually 'on edge'. While some similar attributes were reproduced within TGMP, the prescribed leader identity was, in general, less rigidly 'rational'. Formal programme texts were more broadly based and open-ended: 'learning' and 'sharing' appeared alongside 'decisiveness and risk-taking', regulated within group processes and ongoing feedback. Although some participants noted that the 'softer' competencies received less attention over time, programme practices appeared to construct a TGMP 'leader' self that was more inclusive and flexible.

The leader as English-speaking and 'Western'. The idealized 'leader' identity in these LDPs also prescribed language, accent, and cultural background. Both global programmes prioritized an Englishspeaking leader identity. Participants were required to speak, write, and present in English with fluency and confidence. Indeed, the TGMP programme director wondered "whether we are sometimes looking only at that" (TGMP Dir F). In both settings, participants spoke of tension and anxiety around enacting a competent, English-speaking self. "For me the (programme) lows were the moments of doubt standing in front of the audience and having to explain something, trying to be natural, and English is not my mother tongue..." (TGMP19 M). Another said, "I got feedback that I had to speak out more, so I did. A lot of us (non-native English-speakers) got that feedback. It could be brutal" (TGMP17 M).

Both programmes largely ignored cultural diversity along a range of dimensions. This included macro-cultural differences, the understanding of which was ostensibly part of the rationale for participant selection, yet was not pursued as part of learning how to lead in an international setting. On the contrary, open criticism, which at times had an explicit cultural basis, was a form of identity regulation that was significant for several participants in both LDPs. This was objectionable to some, 
and likely increased the discomfort of many participants. In GAL, the forced ranking clearly contributed to this effect. Speaking of the requirement to give individuals direct and personal feedback, one participant stated, "In the culture where I grew up, it would be considered very insulting" (GAL3 M). During an interview a year after the programme ended, a GAL member of East Asian cultural background recalled the impact the exercise had on him:

From a Western perspective, ranking your peers is not a big deal; everyone is an open book. But on me it had a big impact. You don't spill out your guts about other people, all out there on a flipchart. This was a major barrier for me (GAL11(2) M).

A further participant spoke of holding back more 'natural' behaviours given that others, especially in his project group, saw him as 'different'. This theme arose in both LDPs, and centered on a perceived requirement to suppress one's usual ways of being and communicating, or to change these explicitly, in order to conform to a Western model. Such compliance seemed necessary to thrive, and indeed to survive within GAL.

In sum, programme identity regulation sensitized participants both to the corporate importance ascribed to particular leader identities, and the concomitant requirement to re-align their identities with the prescribed leader ideal. To a greater or lesser extent, and through a number of sometimes contradictory practices, these LDPs prescribed the ideal leader as special and deserving, continually pressured and on edge, hyper-rational and decisive, and English-speaking and Western creating considerable ambiguity and insecurity in the process.

\section{Reinforcing the idealized identity}

A number of practices subsequently reinforced this leader identity within the LDPs: an overarching worldview, hooking practices, mandated self-reflection, and 'confession'.

An overarching worldview. One of the ways that religious and other organizations sustain a group identity is by offering an overarching framework or 'worldview' for making sense of oneself and one's place in the world (Greil \& Rudy, 1983). For GAL, a worldview in which 'good' organizations must 
be lean, rational, merit-based, and 'anti-bureaucratic' formed an important backdrop underlining the prescribed leader model. "We are looking for a cultural shift. The company has followed a traditional, very British model, always aiming for consensus. It is conflict-averse. We are shifting to a much more American focus - a results focus" (GAL Dir M). The Director General was often viewed as a symbol of this 'new way'. Participants referred to him as 'an absolute dynamo' with a 'take no prisoners' style who 'did not suffer fools'. GAL requirements for speed, aggressiveness, and total dedication to the job formed a type of 'master attribution scheme' (Snow \& Machelek, 1984).

The TGMP worldview was more generic, although not culturally neutral. It centered on promoting 'progressive' management techniques, including an emphasis on 'ethical business'. Demonstrating knowledge of such techniques indicated that one had adopted the desired leader identity. Participants attended a mini-course on ethics and were encouraged to question the company's practices and suggest improvements. Prospective leaders were seen as carriers of the change, 'apostles' educated separately from the rank and file who were expected to take on a special role in future enactment of the worldview (Ackers \& Preston, 1997).

Hooking practices. A number of 'hooking practices' (Greil \& Rudy, 1983) had the effect of sustaining or increasing participants' attachment to the espoused leader identity in both LDPs. One hooking practice was the expectation of personal sacrifice (Grint, 2010). As stated above, participants paid a high price to be present on the programmes, sacrificing family and personal time to succeed. A senior GAL participant missed his own $50^{\text {th }}$ birthday party; in TGMP, a participant missed his partner's early stages of labour for their first child. Over time, such investments encouraged adoption of the group identity. A further hooking practice was the provision of a close social network - a ready-made community that individuals would not otherwise have had. The physical encapsulation of members during the off-site workshops, more or less cut off from outside contact, facilitated this effect (Pratt, 2000a). For GAL, the workload itself required intensive contact with team members, with little time for other activities. Participants of both LDPs spoke of feeling 'tied in' or 'very connected'. Such intensive social and affective ties have again been linked to processes of 'conversion' (Snow \& Machelek, 1984). viii $^{\text {ii }}$ 
Mandated self-reflection. Prescribed leader identities were further sustained through mandated self-reflection, a powerful mechanism for reinforcing the leader identity in both LDPs. Compelled to think about personal 'strengths and weaknesses', participants were expected to develop an understanding of where they were aligning themselves with the espoused leader model and where they were not. This type of 'normalizing' became more potent when participants compared previous experiences and 'past selves' to this new worldview. Several GAL participants spoke about receiving feedback that caused them to recall their own previous leader selves. One woman took it as a revelation when she was informed that her behaviour showed weak engagement with her team - she nonetheless accepted the critique from her coach, agreeing to 'change'. Others indicated that they had indeed 'changed' as a result of the programme. "I'm better now," said one woman, "I can push more" (GAL15 F). These participants were not expressing a simple increase in skill, but speaking reflexively about being different as a result of the programme.

Confessions to elders. In Foucault's analysis the confession is central to the way that power relations are often reproduced through self-disciplining practices. Confession was an important feature particularly within GAL, where participants were encouraged to admit lapses from performing the prescribed leader identity. Two female participants spoke about sharing weaknesses and concerns with their programme sponsors. One had explained to her sponsor that conflicts in her personal life were damaging her performance in the LDP, adding that "[my sponsor] was a real father figure to me. He really understands me" (GAL14 F). Through such confessions, the individual shows a willingness to be judged by higher-status leaders. Indeed, encounters with such 'elders' are often important features of 'rites of passage' (Hallier \& James, 1999), powerfully drawing participants 'into the fold' while insisting on self-disclosure to the gaze of judgment. ${ }^{i x}$

\section{Investiture and divestiture in leadership development}

Although both LDPs targeted identities by prescribing and reinforcing idealized leader identities, important degrees of difference also emerged in the two sites. Within TGMP, more open-ended control practices were evident, whereas GAL was characterized by greater 
disciplinary and at times coercive processes. We label these 'investiture' and 'divestiture' strategies of leadership development respectively, adapting from Van Maanen (1978). An investiture approach generally supports and augments existing identities, enacting looser control. Conversely, divestiture tends to diminish extant identities through tighter control and higher stakes of non-compliance embedded in its design, producing a narrower leader self.

Practices of investiture defined the approach at TGMP, including participant choice with regard to joining the programme, developmental peer feedback, and external non-political coaching and project sponsorship. Candidates for TGMP appeared to be taken 'as they are': any employee of appropriate managerial rank was invited to apply. Selection was based on relatively transparent criteria and participants were selected for existing skills relating to a considerable range of abilities. In this more relaxed regime, participants were not required to become uniform upon entry through a forced sense of equality or disregarding of rank. The leader identity prescribed in TGMP was, in general, less exclusive. Formal programme texts were more broadly based, and the design of the programme constructed a self that was more open-ended and less culturally rigid than the model within GAL. Yet the stringent requirement for proficient, even non-accented English remained, which operated more as a divestiture practice.

The investiture strategy aligned with the corporate objective of retaining senior staff in a company where this was difficult due to the nature of its industry. Although a heavy restructuring began during the programme and continued in subsequent months, TGMP participants were all retained and one-third received promotions during or shortly after the programme. In one-year later research interviews, all three TGMP interviewees had been promoted, and were building on their experience.

In contrast, the GAL case exemplifies a divestiture strategy of leadership development. This is illustrated by three particular practices: compelled selection, forced ranking, and termination. Rather than the broadly developmental ethos of TGMP, the divestiture strategy of GAL focused on participant insecurity as a tool of control through identity regulation. Increased participant insecurity could take 
material (e.g., in terms of employment and career progress) and/or symbolic (e.g., in terms of identity and self-worth) forms.

Compelled selection revealed the employer's willingness to remove a degree of autonomy from participants, who were required quite literally to leave behind their regular lives and identities in order to participate. Deferrals to a later cohort were not permitted; some GAL participants spoke about fearing for their jobs if they did not comply. Thus, conditions of compulsion and increased insecurity were associated with the hierarchical processes of divestiture. Arguably, the programme exploited people's aspirations and desire to build personal security for themselves through a promise of opportunities that arose only for a very few.

Forced ranking and self-criticism were present most clearly in the peer ranking exercise, where consequences of receiving a low rank proved to be particularly significant. The director confirmed that senior management used the rankings to assist in deciding who would be most likely to succeed as senior leaders, who were candidates for promotion, and who should be fired. These decisions crucially influenced participants' futures, as well as their identities and sense of self-worth. In one senior participant's words:

This organization is tough, inhuman at times. The fear factor was based on reality, as opposed to some notional cultural issue... (Participants) are watching their colleagues getting pushed out because they're not performing, and here they are being told that they've got deficiencies that they need to improve on (GAL24 M).

Different orientations to self-reflection in the two LDPs are also indicative of the divestiture/ investiture distinction. TGMP reflections focused on developing skills, whereas at GAL reflection increased the tension between not being good enough, and a desire to be different, forcing individuals "to question who they have been and who they are attempting to be" (Ashforth, Harrison \& Corley, 2008, p. 342). Continual exposure through mandated selfreflection and 'confession' ensured that this tension was ever-present. The leader self was tightly defined and controlled, making 'healthy' identity development particularly difficult (Brown \& Starkey, 2000). 
Finally, GAL's practice of firing (certain) participants during and soon after the programme did not appear to be solely because of individuals' purported lack of fit with the leader self, but could also be due to their questioning of the programme approach. As noted previously, four GAL participants were involuntarily terminated during or just after the programme. One was a very senior woman who was fired, according to the programme director, because of her overt 'belligerence' regarding the Director General's approach to change in the organization. Paradoxically, the programme director acknowledged that this particular manager had 'edge', entrepreneurial spirit, and initiative, as well as a willingness to speak candidly about her views, but she was fired in the interest of maintaining tight normative discipline. Another of the four was a man found to be 'preoccupied' with family matters (in this case, elderly parents), according to the director. Underlining the powerful disciplinarity within the divestiture model, survivors' security was thus targeted through the concurrent underlying message that "next time, it could be me."

\section{Resisting Selves in Global LDPs}

The foregoing investiture and divesture regimes can be distinguished by the degree of participant insecurity experienced within their processes. Yet, while these disciplinary processes generated considerable accommodation and compliance, they also prompted surprising levels of dissent and opposition. Although studies of resistance have rarely involved 'leaders', aspiring leaders, or senior organizational members more generally, we recognized important forms of resistance in participants' accounts (c.f. Zoller \& Fairhurst, 2007).

In the more supportive and developmental context of TGMP, participants seemed more at ease with what they were asked to do. With regard to the leader self produced in the programme, they were more neutral in their responses. Nonetheless, forms of resistance helped participants to produce autonomous identities (Prasad \& Prasad, 1998) in this context of relatively soft regulation of leader identities. In the divestiture regime of GAL, on the other hand, uncertainty and insecurity were palpable: "It was a bit like living through a tsunami," as one GAL participant described the programme. 
Some people sought to subvert the impact of this metaphorical tsunami by asserting their own subjective control and 'self-determination'.

Previous literature has questioned the significance of resistance where control is normative or consists mainly in the control of subjectivity, suggesting that a) resistance is rife with ambiguities and contradictions, sometimes resulting in oppositional actors producing the very subjectivities sought by employers (Kondo, 1990; Collinson, 1992; Fleming \& Spicer, 2007), and b) that, as a result, resistant actors may fail to call into question the overarching discourses to which they are subjected through their identity work, and thus resistance may not bring change (c.f. Thomas \& Davies, 2005). Here we draw on our more longitudinal data in order to build a counter-argument. Two types of resistance from managerial participants emerged within the LDPs we studied, which we label 'assertion of alternate selves' and 'exit'.

Assertion of alternate selves. In TGMP, we found a quite overt refusal to go along with certain mandated activities connected to enacting the leader self of the programme. One example was the refusal of some participants to participate in formal networking sessions. Refusal or rejection of this part of the programme was expressed with a kind of confident abandon or disregard, revealing a view that such headquarters-imposed practices could simply be ignored. In contrast, within GAL we found a more profound if less overt kind of resistance through assertion of self. Some participants engaged in “disguised resistance' (Collinson, 2005). While on the programme, they gave the appearance of conformity to corporate stipulations, which contrasted with their own practices at their home location. In other words, these participants were only performing the identity of the required leader in a knowing (and sometimes exaggerated) way in the context of the LDP and employer HQ meetings. The dramaturgical character of this compliance became clear when juxtaposed with the accounts of noncompliance in their own regular locations. For example, knowing "it's all about the results", one senior GAL manager from an Asian country presented his region's progress in an especially assertive and direct way, focusing on strict financial performance measures during a "worldwide" managers' meeting just prior to GAL completion. The same manager, however, spoke privately of "doing things his own way" 
while in his region, which included not using forced ranking despite being required to do so by Head Office. ${ }^{x}$

Exit. Among TGMP participants, there were no cases of exit or voluntarily leaving the employer. However, four GAL participants voluntarily resigned from the firm within a few months. Three of these were women (there were only 8 women in the original cohort). One woman expressed frustration at the lack of promotion opportunities, another said she wanted to return to her own country after being transferred to headquarters only a year earlier, and another, who had been decidedly uneasy about the programme's approach, returned to higher education. This woman had received very positive feedback from programme leaders and peers for her GAL performance and "game-changing" contributions. At the same time, her account of the programme was quietly but firmly critical. This case illustrates how divestiture can lead to the departure of valued employees. By provoking such unintended consequences, 'strong' versions of divestiture-oriented leadership development can backfire on organizations. Rather than 'paying the price', these senior employees chose not to comply. Neither the programme's disciplinarity, nor related promises of increased status, power, and 'market value' quashed participants' own agency and discretion in their local contexts. Rather, some were able to subvert the 'grand' discourse of leader that operated in the programme, creating their own alternatives.

\section{Discussion - Rethinking global LDPs}

In examining the implications of the foregoing findings, we draw attention to several key points that we hope might inform future research on LDPs, leadership and organizations. First, the research suggests that in addition to being designed to develop leadership competencies, both global programmes sought (wittingly or not) to regulate participants' identities. Our study indicates that processes of identity construction not only reflect a search for respect and dignity, but can also become a site for discipline and control within organizations generally, and in LDPs more specifically. Disciplinary outcomes are especially likely when prescribed identities are tightly defined and when these processes are reinforced by intensified insecurities, both material and symbolic. 
This finding extends earlier work foregrounding disciplinary processes connected to identity and subjectivity, shifting the critical lens onto more senior-level employees engaged in leadership and leadership development (Brown \& Lewis, 2011; Clarke, Brown \& Hope-Hailey, 2009). Whereas the dominant functionalist approach within leadership research tends to conceptualize leaders through a voluntaristic framework, the analysis presented here views LDP identity work as "not only an expression of agency but of power" (Brown \& Lewis, 2011, p. 871). Revealing the significance of power as embedded in context for identity dynamics in LDPs, these findings highlight the importance of critical identity theory for the study of leadership. The emphasis on the practices through which idealized leader selves were resisted also informs an understanding that actors' identity work is always situated, and that its context is invariably rooted in power relations. ${ }^{\mathrm{xi}}$

Second, these regulatory programme practices were found to be complex and somewhat paradoxical. It is increasingly recognized in the literature that 'doing leadership' typically requires leaders to confront and deal with competing pressures and significant dilemmas (Storey \& Salaman 2009). Yet, it can be argued that by underestimating the complexity of the challenges that leaders are likely to confront, neither of these LDPs adequately prepared participants for their future roles. In addition, identity regulation processes reproduced a number of internal tensions and contradictions (frequently discussed by research respondents themselves). In practice, primary discursive features of the programmes were often in tension with one another, such as the programme emphasis on elite or special status, and pressurized work. Exhortations for leaders to be highly independent and to take initiative clashed with the requirement to adhere to a specified leader identity. In the higher-stakes divestiture regime of GAL, the contradictory combination of disciplinary practices and development of leadership was particularly acute, where putative leaders ostensibly valued as decisive agents were expected to accept tightly controlled prescribed identities and become fully identified with the employer. The underlying message that 'to lead, you must conform' thus reproduced significant tensions. While aspiring to be leaders, participants were encouraged, and indeed expected, to act as followers. One unintended outcome of these programme dynamics was that a number of participants engaged in oppositional practices. ${ }^{\text {xii }}$ 
Third, divestiture-investiture differences are significant both in understanding participant responses and more broadly for LDPs and organizations in global contexts. The divestiture-oriented leader development of GAL was characterized by highly disciplinary practices (e.g., compelled selection, forced ranking, and terminations). 'Forced ranking' has been deployed in other companies. It was utilized aggressively at GE by Jack Welch as a 'normal' tool of management, and was also a major feature of 'performance management' at Enron (Tourish \& Vatcha, 2005). Indeed the coercive nature of these practices raises questions about the intrinsic meaning of leadership 'development' which, it could be argued, is radically at odds with the concept of divestiture. 'Development' tends to convey a positive meaning associated with ideas of improvement and betterment, which differ significantly from GAL's processes of compulsion, ego stripping, confession and intensified insecurities. Herein lies another tension and possible contradiction between coercive corporate practices and notions of leadership development. ${ }^{\text {xii }}$

Divestiture-focused leader development also poses a greater risk that diverse perspectives connected to such highly international cohorts will be lost, either through conforming practice, or equally, through resistance in the form of exit or disengagement. Rather than being solely a consequence of the multiple pulls on individuals' identities (c.f. Pratt, 2000b) or of 'normal' anxiety connected to learning, insecurity on GAL was embedded within formal LDP structures and processes, and imposed upon managerial participants in relatively complex ways. The resulting tendency for leader identities to be homogenized ('to lead, you must conform') may be particularly damaging given the myriad research findings concerning the benefits of leadership diversity, especially in large multinational organizations (Ely \& Thomas, 2001; Konrad, Prasad \& Pringle, 2006). Meanwhile, homogenization might be intensified by the departure of actors who may object to the tightly controlled identities on offer in the setting. Notwithstanding a particular subjective power of 'global leader' as an aspirational identity, these actors' resisting practices suggest a willingness and ability to create distance between themselves and the corporate discourse. In this way, and following Pullen and Rhodes (2013), our findings suggest that those who exit may be exhibiting a form of resistance that goes beyond a concern with subjectivity or counter control, and is ethically based. If so, this might be 
important not only empirically but theoretically, given larger debates about resistance within poststructuralist and critical identity research (Contu, 2008; Spicer \& Bohm, 2007; Thomas \& Davies, 2005).

Further, the divestiture-investiture distinction underlines the significance of organizational context, often ignored in research on LDPs. At one level, it would seem yet another paradox that the not-for profit international agency operated a more coercive LDP approach (GAL) than the for-profit corporation (TGMP). Yet GAL was aligned with an aggressive change effort under a new DirectorGeneral with a strong ambition to reshape the firm in the image of a lean, highly 'results'-focused forprofit company. In this sense, identity striving within an LDP may be understood as reflective of identity striving at the organizational level. ${ }^{\text {iv }}$

Finally, the prescribed leader identities examined above also indicate that traditional masculine ideas about leaders and leadership (e.g. in terms of being competitive, aggressive, and privileging of highly rationalistic and non-affective forms of knowledge) continue to persist in global LDPs. Certainly, this appeared to be the default position for both of these international employers, aiming to reinforce dominant masculine and Western views of what leadership is and should be. Notwithstanding evidence that TGMP clearly incorporated methods that edged their leadership in a new direction, these findings question whether global firms may be simply unwilling or unable to move towards more progressive ideas about leadership. This would lend empirical support to Jones' (2006) assertion that many ostensibly international LDPs are highly US-centric and Western in their assumptions, methodologies and aims. Given contemporary developments that assert alternate leadership ontologies -- as relational, affiliative and emergent (Cunliffe, 2009; Denis, Langley \& Sergi, 2012; Gagnon, Vough \& Nickerson, 2012; Trehan, 2007) -- traditional, highly masculine approaches would appear to be counterproductive.

As with all research, it is important to acknowledge that this study is subject to a number of limitations. The use of a case study design, albeit a comparative one, of necessity limits the generalizability of our findings. The more 'extreme' case (of GAL) may be viewed as a particular outlier, arguably far from what might be expected within progressive, global corporations. Yet an unusual or 
'illuminative' case may often have particular insights to offer about a phenomenon, opening up new territory for further research (Patton, 2002; Pratt, 2000b). Moreover, the dual case analysis used here enabled us to recognize the dynamics of programme disciplinarity and participant insecurity in a way that a single case might not, while the shared findings with the somewhat less 'extreme' case of TGMP suggest that several of the overarching practices we uncovered may be transferrable to other settings. A second limitation is that the empirical material represents only a slice of the participants' experiences of these leader programmes. Researchers will inevitably be limited in what they observe and gather through interview data. This was partly mitigated by spending as much time as possible in the two research settings and optimizing the possibilities for data collection.

\section{Conclusions}

This paper has argued that LDPs may be viewed not only as learning processes for leadership competence, but also as relatively intensive regulatory practices designed to target and transform participant identities through processes that may add to or diminish participants' sense of self. Practices in both programmes prescribed a leader identity as special and deserving, pressure-loving and on edge, hyper-rational and decisive, and English-speaking and Western. In addition, the programmes used a range of processes to reinforce these identities: providing an overarching worldview, hooking, mandated reflection, and confessions to elders. Intensifying individuals' visibility and exposure, the disciplinary practices of divestiture were found to increase participants' insecurities about themselves, their identities and career futures in the organization. By comparison, investiture took candidates as they were, in part through the comparatively open-ended production of the idealized leader model. These dynamics were further evident in the tensions and resisting practices of participants that arose in both programmes, with greater implications through exit and enactment of alternate leader selves associated with divestiture.

Our study underscores the importance of power dynamics and disciplinary practices within organizational leadership development. The divestiture approach in particular sought tight control over the character of the next generation of leaders. We have argued that, paradoxically, these 
practices may be contrary to the leadership needs of many contemporary global organizations, through creating relatively narrow, 'Western' leadership models, and by relying on development processes imbued with insecurity and uncertainty. Nonetheless, identity regulatory processes in these two LDPs were frequently experienced as contradictory and inconsistent, sometimes leading to overt or disguised resistance. Further, our dual case comparison suggests that the divestiture model, with its tendency to intensify participant insecurities, is not inevitable - an investiture approach to leadership development can mitigate some of the tensions and contradictions found within a divestiture approach.

In sum, this article has sought to contribute to the development of a more critical framework for studying LDPs. We encourage future research to articulate further the concern with the inseparability of power and context for the identity processes that are often a condition and consequence of leadership development practices. Drawing on critical identity theory, our analysis suggests that future research on leadership and its development should continue to step outside the discrete pedagogical or learning focus with which it is most often associated, and give further recognition to its broader organizational and discursive conditions, effects and implications. Understanding leadership development, including its subjective experience, tensions, and outcomes, requires attention to the discursive context of their production. Equally, understanding the discursive productions of 'leader' (and 'follower') can have important consequences for organization studies.

Further research could also examine the ways in which discourses of leadership development are connected to difference or diversity in organizations, including but not limited to global corporations. We call for more research that names and theorizes homogenization where it occurs, in LDPs and elsewhere, as a way of facilitating better understanding of subjectivity in organizations and its constraint through normalizing practice. Resistance as it is connected to difference and to ethics and an ethical subjectivity are important questions for further work. ${ }^{\mathrm{xv}}$

In such ways the analysis of leadership and leadership development can contribute to the critical study of contemporary organizations more generally. 
Acknowledgements: We would like to thank the anonymous reviewers and OS Co-editor Andrew Brown for their very helpful advice and suggestions.

\section{References}

Ackers,P. \& Preston,D. (2003). Born Again? The Ethics and Efficacy of the Conversion Experience in Contemporary Management Development. Journal of Management Studies, 34, 677-701.

Alvesson,M. \& Willmott,H. (2002). Identity Regulation as Organizational Control. Journal of Management Studies, 39, 619-644.

Alvesson,M. \& Karreman,D. (2000). Varieties of Discourse: On the Study of Organizations through Discourse Analysis. Human Relations, 53, 1125-1150.

Alvesson,M. \& Spicer,A. (2012). Critical Leadership Studies: The Case for Critical Performativity. Human Relations, 65, 367-390.

Ashcraft,K.L. (2005). Resistance through consent? Occupational identity, organizational form, and the maintenance of masculinity among commercial airline pilots. Management Communication Quarterly, 19, 67-91.

Ashforth,B.E., Harrison,S.H., \& Corley,K.G. (2008). Identification in Organizations: An Examination of Four Fundamental Questions. Journal of Management, 34, 325-374.

Avolio, B., Richard,R., Hannah,S., Walumba,F.O., \& Chan,A. (2009). A meta-analytic review of leadership impact research. Leadership Quarterly, 20, 764-784.

Barker,J.R. (1993). Tightening the Iron Cage: Concertive Control in Self-Managing Teams. Administrative Science Quarterly, 38, 408-437

Barley,S.R. \& Kunda,G. (1992). Design and devotion: Surges of rational and normative ideologies of control in managerial discourse. Administrative Science Quarterly, 37, 363-399.

Bergstrom,O., Hasselbladh,H., \& Karreman,D. (2009). Organizing disciplinary power in a knowledge organization. Scandinavian Journal of Management, 25, 178-190. 
Bolden,R. \& Gosling,J. (2006). Leadership Competencies: Time to change the tune? Leadership, 2, 147163.

Brown,A.D. \& Starkey,K. (2000). Organizational identity and learning: A psychodynamic perspective. Academy of Management Review, 25, 102-120.

Brown,A.D. (2001). Organization studies and identity: Towards a research agenda. Human Relations, 54, 113-121.

Brown,A.D. \& Coupland,C. (2005). Sounds of silence: Graduate trainees, hegemony and resistance. Organization Studies, 26, 1049-1069.

Brown,A.D. \& Lewis,M.A. (2011). Identities, Discipline and Routines. Organization Studies, 32, 871-895.

Burns,J.M. (1978). Leadership. New York: Harper Row.

Buus,I.,\& Saslow,S. (2005). The evolution of leadership development. Strategic Human Resource Review, 4, 28-31.

Carden,L.L. \& Callahan,J.L. (2007). Creating Leaders or Loyalists? Conflicting Identities in a Leadership Development Programme. Human Resource Development International, 10, 169-186.

Carroll,B. \& Levy,L. (2008). Defaulting to management: Leadership defined by what it is not. Organization, 15, 75-96.

Casey,C. (1999). "Come, join our family": Discipline and integration in corporate organizational culture. Human Relations, 52, 155-178.

Clarke,D., Brown,A.D., \& Hope-Hailey,V. (2009). Working identities? Antagonistic discursive resources and managerial identity. Human Relations, 62, 1-30.

Collins,J. (2001) Good to Great. New York: Random House. 
Collinson,D. (1992). Managing the Shop floor: Subjectivity, Masculinity and Workplace Culture, Berlin: Walter de Gruyter.

Collinson,D. (1994). Strategies of resistance: Power, knowledge and subjectivity in the workplace. In J. Jermier, D. Knights \& W. Nord (Eds.), Resistance and Power in Organizations. London: Routledge.

Collinson,D. (2003). Identities and Insecurities: Selves at Work. Organization, 10, 527-547.

Collinson,D. (2005). Dialectics of Leadership. Human Relations, 58, 1419-1442.

Collinson,D. (2011). Critical leadership studies. In: A. Bryman, D. Collinson, K. Grint and B. Jackson (eds) The Sage Handbook of Leadership. London: Sage, 179-192.

Collinson,D. (2012). Prozac Leadership and the Limits of Positive Thinking. Leadership, 8, 87-107.

Contu, Alessia. (2008). Decaf resistance: On misbehavior, cynicism, and desire in liberal workplaces. Management Communication Quarterly, 21, 364-379.

Covaleski,M.A., Dirsmith,M.W., Heian,J.B., \& Samuel,S. (1998). The calculated and the avowed: Techniques of discipline and struggles over identity in Big Six public accounting firms. Administrative Science Quarterly, 43, 293-327.

Cunliffe,A.L. (2009). The Philosopher Leader: On Relationalism, Ethics and Reflexivity-A Critical Perspective to Teaching Leadership. Management Learning, 40, 87-110.

Day,D. (2011). Leadership Development. In A. Bryman, D. Collinson, K. Grint, B. Jackson, \& M. Uhl-Bien (Eds.), Sage Handbook of Leadership. London: Sage.

Day,D., Harrison,M., \& Halpin,S. (2009). An Integrative Approach to Leader Development: Connecting Adult Development, Identity and Expertise. New York: Taylor Francis. 
Denis,J.L., Langley,A., \& Sergi,V. (2012). Leadership in the Plural. Academy of Management Annals, 6: 211-283.

DeRue,D.S. \& Ashford,S.J. (2010). Who Will Lead and Who Will Follow? A Social Process of Leadership Identity Construction in Organizations. Academy of Management Review, 35, 1-21.

Delves Broughton,P. (2009). What They Teach You at Harvard Business School. New York: Penguin Books.

Easterby-Smith,M., Thorpe,R., \& Lowe,A. (2008). Management Research. London: Sage.

Ely,R.J. \& Thomas,D.A. (2001). Cultural diversity at work: The effects of diversity perspectives on work group processes and outcomes. Administrative Science Quarterly, 46, 229-273.

Ely,R., Ibarra,H., \& Kolb,D. (2011). Taking Gender into Account: Theory and Design for Women's Leadership Development Programs. Academy of Management Learning and Education, 10, 474-493.

Fairhurst,G.T. (2008). Discursive leadership - A communication alternative to leadership psychology. Management Communication Quarterly, 21, 510-521.

Finch-Lees,T., Mabey,C., \& Liefooghe,A. (2005). 'In the name of capability': A critical discursive evaluation of competency-based management development. Human Relations, 58, 1185-1222.

Fleming,P. \& Sewell,G. (2002). Looking for the good soldier, Svejk: Alternative modalities of resistance in the contemporary workplace. Sociology-the Journal of the British Sociological Association, 36, 857-873.

Fleming,P. \& Spicer,A. (2003). Working at a cynical distance: Implications for power, subjectivity and resistance. Organization, 10, 157-179.

Fleming,P. \& Spicer,A. (2007). Contesting the Corporation: Struggle, Power and Resistance in Organizations. Cambridge: Cambridge University Press. 
Foucault,M. (1972). Archaeology of Knowledge. London: Routledge.

Foucault,M. (1977). Discipline and Punish. London: Allen Unwin.

Foucault,M. (1979). The History of Sexuality (Vol. 1). London: Allen Lane.

Gabriel,Y. (2005). MBA and the Education of Leaders: The New Playing Fields of Eton? Leadership, 1, 147-163.

Gagnon,S. (2008). Compelling Identities: Selves and Insecurities in Global Corporate Management Development. Management Learning, 39, 375-391.

Gagnon,S., Vough,H., \& Nickerson,R. (2012). Learning to lead, unscripted: Teaching leadership through improvisational theatre. Human Resource Development Review, 11, 299-325.

Gordon,R. (2002). Conceptualizing Leadership with Respect to its Historical-Contextual Antecedents to Power. Leadership Quarterly, 13,151-167.

Greil,A.L. \& Rudy,D.R. (1983). Conversion to the World View of Alcoholics Anonymous: A Refinement of Conversion Theory. Qualitative Sociology, 6, 5-28.

Grint,K. (2010). The Sacred in Leadership: Separation, Sacrifice and Silence. Organization Studies, 31, 89-107.

Hallier,J. \& James,P. (1999). Group Rites and Trainer Wrongs in Employee Experiences of Job Change. Journal of Management Studies, 36, 45-67.

Haslam,S.A., Reicher,S.D., \& Platow,M.J. (2011). The New Psychology of Leadership: Identity, Influence, and Power. Hove: Psychology Press.

Hodgson,D. (2005). 'Putting on a professional performance': Performativity, subversion and project management. Organization, 12, 51-68. 
Hogg,M. (2001). A Social Identity Theory of Leadership. Personality \& Social Psychology Review, 5, 184200.

Hughes,P.D. \& Grant,M. (2007). Learning and Development Outlook 2007. Ottawa, ON: Conference Board of Canada.

Jamrog,J.J. (2005). Leading into the Future: A Global Study, 2005-2015. New York: American Management Association.

Jaros,S. (2012). Identity and the Workplace: An Assessment of Contextualist and Discursive Approaches. Tamara: Journal for Critical Organization Inquiry, 10, 45-59.

Jermier,J.M., Knights,D., \& Nord,W.R. (1994). Resistance and power in organizations. London: Routledge.

Jones,A. (2006). Developing What? An Anthropological Look at the Leadership Development Process Across Cultures. Leadership, 2, 481-498.

Kärreman,D. \& Alvesson,M. (2004). Cages in tandem: Management control, social identity, and identification in a knowledge-intensive firm. Organization, 11, 149-175.

Kenny,K., Whittle,A., \& Willmott,H. (2011). Understanding Identity and Organizations. London: Sage.

Kondo,D.K. (1990). Crafting Selves: Power, Gender and Discourses of Identity in a Japanese Workplace. Chicago: University of Chicago Press.

Konrad,A.M., Prasad,P., \& Pringle,J.K. (2006). The handbook of workplace diversity. London: Sage Publications.

Locke,K. (2001). Grounded Theory in Management Research. Thousand Oaks: Sage. 
Lord,R.G. \& Brown,D.J. (2004). Leadership Processes and Follower Self-Identity. New Jersey: Lawrence Erlbaum.

Lord,R.G. \& Hall,R.J. (2005). Identity, deep structure and the development of leadership skill. Leadership Quarterly, 16, 591-615.

Mabey,C. \& Finch-Lees,T. (2008). Management and Leadership Development. London: Sage.

Mabey,C. (2012). Leadership Development in Organizations: Multiple Discourses and Diverse Practice. International Journal of Management Reviews, forthcoming.

McCulloch,G. (1991). Philosophers and Kings: Education for Leadership in Modern England. Cambridge: Cambridge University Press.

Mumby,D.K. (2005). Theorizing Resistance in Organization Studies: A Dialectical Approach. Management Communication Quarterly, 19, 19-44.

Nicholson,H. \& Carroll,B. (2013). Identity undoing and power relations in leadership development. Human Relations, forthcoming.

Nye,J. (2008). The Powers to Lead. Oxford: Oxford University Press.

Obodaru,O. (2012). The self not taken: How alternative selves develop and how they influence our professional lives. Academy of Management Review, 37, 34-57.

Patton,M.Q. (2002), Qualitative Research and Evaluation Methods. Thousand Oaks: Sage Publications Inc.

Petriglieri,G. \& Stein,M. (2012). The Unwanted Self: Projective Identification in Leaders' Identity Work. Organization Studies, 33, 1217-1235.

Prasad,A. \& Prasad,P. (1998). Everyday struggles at the workplace: The nature and implications of routine resistance in contemporary organizations. In P. A. Bamberger \& W. J. Sonnenstuhl (Eds.), 
Research in the sociology of organizations, 15: Deviance in and of organizations (pp. 225-257). Stamford: JAI.

Prasad,P. \& Prasad,A. (2000). Stretching the Iron Cage: The Constitution and Implications of Routine Workplace Resistance. Organization Science, 11, 387-403.

Prasad,P. (2005). Crafting Qualitative Research: Working in the post positivist traditions. New York: ME Sharpe.

Pratt,M.G. (2000a). Building an ideological fortress: The role of spirituality, encapsulation and sensemaking. Culture and Organization, 6, 35-69.

Pratt,M.G. (2000b). The good, the bad, and the ambivalent: Managing identification among Amway distributors. Administrative Science Quarterly, 45, 456-493.

Pullen,A. \& Rhodes,C. (2013). Corporeal ethics and the politics of resistance in organizations. Organization, forthcoming.

Rhodes,C. (2009). After Reflexivity: Ethics, Freedom and the Writing of Organization Studies. Organization Studies, 30: 653-672.

Schwalbe,M., Godwin,S., Holden,D., Schrock,D., Thompson,S., \& Wolkomir,M. (2000). Generic processes in the reproduction of inequality: An interactionist analysis. Social Forces, 79, 419-452.

Shamir,B., House,R.J., \& Arthur,M.B. (1993). The motivational effects of charismatic leadership: A selfconcept based theory. Organization Science, 4, 577-594.

Snow,D. \& Machalek,R. (1984). The sociology of conversion. Annual Review of Sociology, 10, 167-190.

Spicer,A. \& Bohm,S. (2007). Moving Management: Theorizing Struggles against the Hegemony of Management. Organization Studies, 28, 1667-1698.

Stake,R.E. (1995). The art of case study research. Thousand Oaks: Sage. 
Storey,J. \& Salaman,G. (2009). Managerial dilemmas. Chichester: John Wiley.

Strauss,A. (1987). Qualitative analysis for social scientists. Cambridge, England: Cambridge University Press.

Thompson,P. (1993). Postmodernism: Fatal distraction. In J. Hassard \& M. Parker (Eds.), Postmodernism and organizations (pp. 183-203). London: Sage.

Thomas,R., Mills,A., \& Mills,J.H. (Eds.). (2004). Identity Politics at Work: Resisting Gender, Gendering Resistance. New York: Routledge.

Thomas,R. \& Davies,A. (2005). Theorizing the Micro-politics of Resistance: New Public Management and Managerial Identities in the UK Public Services. Organization Studies, 26, 683-706.

Thomas,R. (2009). Critical management studies on identity. In M. Alvesson, T. Bridgman, \& H. Willmott (Eds.), The Oxford Handbook of Critical Management Studies. Oxford: Oxford University Press.

Thomas,R., Sargent,L.D., \& Hardy,C. (2011). Managing Organizational Change: Negotiating Meaning and Power-Resistance Relations. Organization Science, 22, 22-41.

Thornborrow,T. \& Brown,A. (2009). 'Being Regimented': Aspiration, Discipline and Identity Work in the British Parachute Regiment. Organization Studies, 30, 355-376.

Tourish,D. (2013). The Dark Side of Transformational Leadership. London: Routledge.

Tourish,D. \& Vatcha,N. (2005). Charismatic leadership and Corporate Cultism at Enron: The Elimination of Dissent, the Promotion of Conformity and Organizational Collapse. Leadership, 1, 455-480.

Trehan,K. (2007). Psychodynamic and Critical Perspectives on Leadership Development. Advances in Developing Human Resources, 9, 72-82. 
Townley,B. (1993). Foucault, Power, Knowledge and its Relevance for Human Resource Management. Academy of Management Review, 18, 518-545.

Van Maanen,J. (1978). People Processing: Strategies of Organizational Socialization. Organization Dynamics, Summer. 19-36.

Willmott,H. (1993). Strength Is Ignorance, Slavery Is Freedom: Managing Culture in Modern Organizations. Journal of Management Studies, 30, 515-552.

Ybema,S. (2010). Talk of change: Temporal contrasts and collective identities. Organization Studies, 31, 481-503.

Zanoni,P. \& Janssens,M. (2007). Minority Employees Engaging with (Diversity) Management: An Analysis of Control, Agency and Micro-Emancipation. Journal of Management Studies, 44, 1371-1397.

Zoller,H. \& Fairhurst,G. (2007). Resistance leadership: The overlooked potential in critical organization and leadership studies. Human Relations, 60, 1331-1360.

\section{Author biographies:}

Suzanne Gagnon is Assistant Professor of Organizational Behaviour in the Desautels Faculty of Management, McGill University. She studies discursive and material constructions of identity, difference and inequality and their effects, including for leadership and situated leadership actors. She has a particular interest in how critical leadership and diversity research can contribute to organizational change. She is currently co-lead for a five-year Community University Research Alliance (CURA) examining leadership diversity in large employers, supported by Canada's Social Sciences and Humanities Research Council (SSHRC). Suzanne has published articles on diversity, ethics and leadership in journals including Organization Studies, Journal of Business Ethics, Management Learning, Human Resource Management Journal, and Human Resources Development Review.

David Collinson is Chair of Leadership \& Organisation and Head of the Department of Management Learning \& Leadership at Lancaster University Management School. He is the founding Co-editor of the 'Leadership' journal and founding Co-organiser of The International Conference on Studying Leadership. David has published extensively on critical approaches to leadership, organization and management, with articles appearing in many leading academic journals such as Organization Studies; Human Relations; Journal of Management Studies; Leadership Quarterly; Organization; Gender, Work and Organization; Leadership, and Work, Employment \& Society. He has published 13 books including The Sage Handbook of Leadership (2011) and Major Works in Leadership Studies Volumes 1-1V (2011). 
Table 1: Nationalities and Current Work Locations of Programme Participants

\begin{tabular}{|c|c|c|c|}
\hline TGMP & & GAL & \\
\hline Nationality & Current work location & Nationality & Current work location \\
\hline Turkish & Turkey & American & Costa Rica \\
\hline Lithuanian & Switzerland & Canadian & Canada \\
\hline Greek & Switzerland & British & Canada \\
\hline Malaysian & Malaysia & Canadian & Canada \\
\hline French & Switzerland & British & Switzerland \\
\hline Russian & Russia & Slovakian & Czech Republic \\
\hline Australian & Netherlands & South African & South Africa \\
\hline Lithuanian & Lithuania & French & Canada \\
\hline American & Switzerland & French & Switzerland \\
\hline Pakistani & Switzerland & Canadian & Canada \\
\hline French/Spanish & France & British & Canada \\
\hline Indian & New Zealand & Chinese & China \\
\hline Dutch & Netherlands & & \\
\hline Portuguese & Portugal & Swedish & Switzerland \\
\hline American & USA & Pakistani & Switzerland \\
\hline British & Switzerland & Malaysian & Singapore \\
\hline German & Switzerland/Germany & Swiss & Switzerland \\
\hline Venezuelan & USA & Canadian & Canada \\
\hline Swiss & Switzerland & Venezuelan & Panama \\
\hline Armenian & Armenia & Lebanese & Lebanon \\
\hline
\end{tabular}




\begin{tabular}{|ll|ll|}
\hline French & Switzerland & French & Canada \\
Kazakhstan & Switzerland /Russia & British & Switzerland \\
Spanish & Spain & French/Spanish & Spain \\
Vietnamese & Viet Nam & British & Switzerland \\
French & Switzerland & Sri Lankan & Singapore \\
\hline
\end{tabular}

(Work locations are given by country only in order to retain anonymity.)

Table 2: Overview of Interviews Conducted

\begin{tabular}{|l|c|c|}
\hline Role & $\begin{array}{l}\text { No. of } \\
\text { interviewees }\end{array}$ & $\begin{array}{l}\text { No. of } \\
\text { interviews }\end{array}$ \\
\hline Programme participants, GAL & 24 & 32 \\
Programme director, GAL & 1 & 5 \\
$\begin{array}{l}\text { Programme coaches, GAL (all } \\
\text { former programme } \\
\text { participants) }\end{array}$ & 4 & 5 \\
\hline $\begin{array}{l}\text { Programme participants, } \\
\text { TGMP }\end{array}$ & 23 & 27 \\
Programme directors, TGMP \\
(one also a former \\
participant) \\
Other HR specialist staff
\end{tabular}




\section{Footnotes}

${ }^{\mathrm{i}}$ According to Foucault, it is through the web of relations in which power and resistance co-exist that meaning is negotiated, challenged and transformed (Thomas et al. 2011). Power is multidirectional, productive of creative tensions, enabling as well as subordinating.

ii Three central characteristics help to explain Foucault's conceptualization of discourse: first, an interest in how discourses come into being, focusing on internal rules that govern what can be spoken about and whose ideas are considered to be legitimate; second, effects of any discourse are more important than its so-called truth validity, directing attention to the constitutive nature of discourses as "practices that systematically form the objects of which they speak" (Foucault, 1972, as cited by Prasad, 2005, p. 251); and third, Foucault uses the term discourse to emphasize its materialistic implications. It is not limited to language and representation as some critics have argued (e.g. Thompson, 1993), but is rather formed and operates at the intersection of language and the material world.

iii The first author conducted the fieldwork while both authors undertook the writing and analysis. Participant interviews were responsive and open-ended. Questions focused on participants' accounts of the following themes: personal and group learning; project groups; selection and evaluation processes; impact of the diverse cultural backgrounds represented; interpersonal dynamics; careers and future plans; expectations of programme participation; connections to their regular jobs; any other issues arising. We probed for more detailed accounts of particular programme elements as they emerged in the interviews. With the programme directors, interviews focused on background information about programme design, history and purposes, the relationship of the programme to corporate objectives, programme details including selection, evaluation and outcomes, perceived programme effectiveness, future plans for leader development and any other issues arising.

${ }^{\text {iv }}$ The interviews concerned their evolving views of the programmes, use of programme learning in their work, career development, job security and future prospects, ongoing networks with programme members, and continuing involvement, if any.

${ }^{v}$ A number of limitations characterized our choices in analysis. Some detail and nuance was necessarily neglected in building a theoretical understanding of the empirical material. As our objective in this study was to understand practices of formal LDPs, individual-level narratives were not our primary category of analysis. A preliminary (and complementary) study had considered individuals' identity practices (Gagnon, 2008).

${ }^{v i}$ The names of these documents, which appeared on the company portal for information and application to the 'GAL' programme, are confidential.

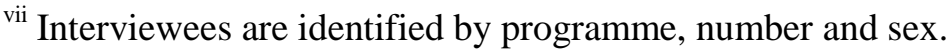

viii Their importance here was perhaps underlined by one GAL member's albeit ambiguous sense of loss upon programme completion: "Afterwards it was the strangest thing, it all just dropped. ... I felt like an orphan, everything totally disappeared" (GAL6 F).

${ }^{\text {ix }}$ Confessional practice did not arise in the TGMP data, perhaps due to the absence of coaches internal to the firm.

${ }^{x}$ We note Obodaru's recent conceptualization of 'alternative selves' drawing on psychological perspectives (2012), and underline the importance of how assertion of alternate selves can be a form of resistance embedded in particular contexts. 
${ }^{\mathrm{xi}}$ Uncritical studies of identity tend artificially to separate self-construction from power dynamics and to view context as separate from power.

xii A further embedded tension here concerned the singling out of 'special' people for leader development, in combination with a 'fear factor' like that in GAL, which may foster acute preoccupation with self rather than a 'superhuman' leadership capability apparently sought by the employer. In both these LDPs such processes also risk breeding hubris in aspiring leaders, a result of having survived a pressurized ordeal but one through which participants' special status and their future elite self is continually constructed and re-affirmed (Thornborrow \& Brown, 2010; Ybema, 2010). Such discourses conjure up bygone images of the 'fields of Eton' where education was a primary mechanism for the reproduction of the British elite (Gabriel, 2005; McCulloch, 1991). Equally, the encouragement of aspiring leader hubris in LDPs may be seen as validating identity through elitism, similar to the recent account of an MBA student at Harvard Business School (HBS) which documents how HBS students are persistently assured of their elite status as future business leaders (Delves Broughton, 2009). Delves Broughton argues that the HBS approach tends to elevate students' self-belief to even greater heights, thus undermining humility - arguably, a key requirement for more participatory styles of leadership decision making (see e.g. Collins 2001).

xiii Indeed one anonymous reviewer of this article helpfully observed that reference to divestiture as 'development' could in itself be seen as using language in ways that disguise the elements of coercion and compulsion foregrounded in the GAL programme.

${ }^{14}$ Here we would wish to distinguish our analysis from one other article that we are aware of on LDPs (currently awaiting publication at the time of writing) which posits identity 'undoing' within a universityled programme (Nicholson \& Carroll, forthcoming). In this case identity construction is presented in a largely individualistic and interactional form, with little consideration of discursive context. Whilst the importance of power is intimated early in the article, the argument is characterized by is a dualistic tendency to separate power and identity: a theoretical discussion about power precedes an empirical section on identity dynamics (which neglects power dynamics). The liberal context and content of the programme, which is delivered at a university and designed using social constructionist perspectives, makes it rather less typical of mainstream/commercial LDPs, as do issues of proximity in that one of the authors is also one of the programme facilitators (itself calling for greater reflexive analysis). By contrast, a central concern of our article is to emphasize the inter-related significance of context, power and identity for understanding LDPs, and to consider how these important factors may be inextricably linked and mutually-reproducing in particular practices.

${ }^{\mathrm{xv}}$ Interestingly, Alvesson and Willmott's theory of identity regulation discussed earlier does not engage with difference in any overt or explicit sense, but may help lay the ground for its greater emphasis in future empirical studies. 